\title{
An OFDM PAPR Reduction Technique using Perfect Random Sequences and DAPM-DWT for 5 G Technology
}

\author{
Puneeth Kumar D N ${ }^{1}$ and M N Eshwarappa ${ }^{2}$ \\ ${ }^{1}$ Visvesvaraya Technological University, Belagavi, India. \\ ${ }^{2}$ Department of Electronics \& Communication Engineering, \\ Sri Siddhartha Institute of Technology, Tumkur, India.
}

\section{ABSTRACT}

Orthogonal frequency division multiplexing (OFDM) systems suffers from high peak to average power ratio (PAPR). In this paper, PAPR is reduced for OFDM systems for 5G wireless networks by proposing a scheme which employs perfect random sequences to reduce the PAPR for different channels like A White Gaussian Noise (AWGN), flat fading channel and frequency selective channel with DWT, DFT and DCT by using Differential Amplitude and Phase modulation (DAPM), Quadrature Amplitude Modulation (QAM) and Pulse Amplitude Modulation (PAM) modulation techniques. Simulation results show that the proposed method has less PAPR value for DAPM-DWT and less BER for DAPM-DWT for flat fading and frequency selective channels and also as compared with DCT, DFT with QAM and PAM modulation techniques.

KEY WORDS: OFDM, PAPR, RANDOM SEQUENCES, 5G, DWT, DAPM.

\section{INTRODUCTION}

OFDM could be a modulation with many carriers that is employed in several wireless communication standards and this method has higher spectral potency and has better information rates in channels (G. Wunder et.al.,2013).In DWT based OFDM cyclic prefix may not be required because of the overlapping properties and this avoids ISI because the subcarriers are of restricted length. The linear power amplifier cause the inter carrier modulation which produces large peak amplitudes in the OFDM signal, this causes large PAPR and BER. OFDM is having high PAPR which may be the disadvantage within the multicarrier transmitted signals (J G Proakis, 1995).

\section{ARTICLE INFORMATION}

*Corresponding Author: puneethdnkumar@gmail.com Received 11th Oct 2020 Accepted after revision 27th Dec 2020 Print ISSN: 0974-6455 Online ISSN: 2321-4007 CODEN: BBRCBA

Thomson Reuters ISI Web of Science Clarivate Analytics USA and Crossref Indexed Journal

\section{Clarivate
Analytics}

NAAS Journal Score 2020 (4.31)

A Society of Science and Nature Publication,

Bhopal India 2020. All rights reserved.

Online Contents Available at: http//www.bbrc.in/

Doi: http://dx.doi.org/10.21786/bbrc/13.13/7
The encoding used by the $5 \mathrm{G}$ networks is OFDM that is almost same as that to the encoding used by 4G LTE. Compared to the LTE, the air interface has flexibility and lower latency and 4G has identical airwaves. Because of the economical encoding, the $5 \mathrm{G}$ radio system can go with $30 \%$ higher speed. Also $5 \mathrm{G}$ networks use channels larger than $4 \mathrm{G}$ networks. with $20 \mathrm{MHz}$ secured up to $100 \mathrm{MHz}$ with exploitation of the foremost amount as $800 \mathrm{MHz}$ at a time (paolo Banelli et. all., 2014).

Within the literature several strategies are planned for reducing the PAPR in OFDM systems (S Zhang, 2016 \&t S P Delmarco, 2018) .In (Si-Yu Zhang et. all., 2020) a scheme that reduces PAPR consists of 2 stages. The primary stage that constructs a collection of QAM outcomes with the littlest potential range of IFFTs and also the second stage relies on the changed category III SLM (Selected Mapping) scheme planned that a bank is of parallel blocks. Every block uses circular convolution and circular shifting to generate additional sequences from QAM outcomes by passing this information via collection of many blocks. In (Si- Yu Zhang et. al., 2018) the changed version of the standard SLM technique is planned. during this paper while not increasing the quantity of IFFTS, the

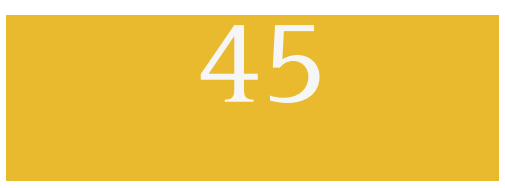


performance of the SLM scheme is improved with respect to PAPR and also the simulation results shows that this technique has less PAPR performance than the standard SLM for a given range of IFFTs with no further facet info.

In (Puneeth Kumar D N et al., 2020) DWT-DAPM technique is employed to scale back the PAPR and BER within which the PAPR is reduced to 4.497 at $10-3$ CCDF(Complementary Cumulative Distributive function) and different transforms like DFT,DCT area unit used and area unit modulation techniques like QAM and PAM area unit used and also the results area unit compared. In (H B Jeon et. al., 2011), the procedure quality while not touching BER and PAPR by exploitation the extra memory to save lots of the additive mapping signal sequences is reduced with QAM modulation technique. In (Hyun- Seung Joo et.al.,2017) two partial transmit sequence (PTS) while not facet info (SI) area unit planned for reducing the PAPR of OFDM signals and from the numerical analysis the performance of the BER isn't degraded when put next with the standard PTS with good SI. In (Pingyuan et. al., 2015) tone reservation technique is employed within which the kernel matrix in the time domain to come up with reducing the height of the signals with the kernel generated in time domain onetime or offline and within the peak reduction iterations there are not any IFFT/FFT operations and also the simulation results shows that hardware and time quality of this scheme area unit. In (H B Jeon et. al., 2009) SLM technique supported bit exploitation QAM modulation technique within which the magnitudes and phases are modified.

In this paper PAPR reduction methodology using the transforms like DWT, DFT and DCT by applying many modulation schemes such as PAM, DAPM and QAM with perfect random sequences as well as 10 iterations OFDM system has been proposed considering 64,128,512 sub-carriers and the input message size of 1500 bits. The performance analysis is done based on PAPR and BER for this system.

Figure 1: Concept of Conventional SLM technique.

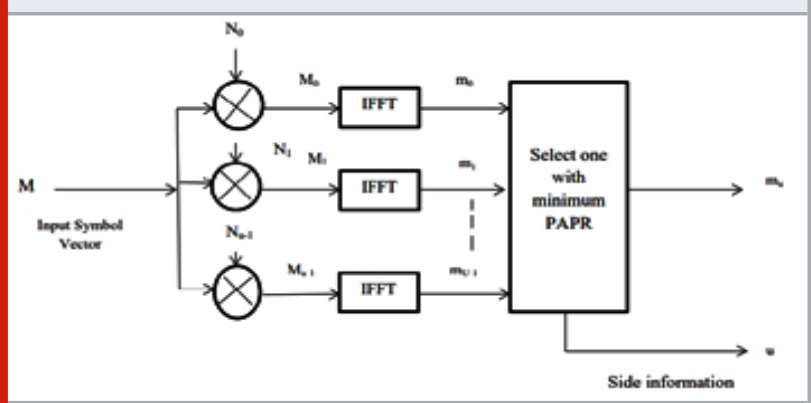

Organisation of the paper: Section II deals with the SLM scheme where as in the next section better proposed method is discussed. Research outcomes are discussed in the section IV and in the section V conclusion inference are drawn.
The Conventional SIm Technique: Here short information concerning SLM technique is mentioned. For the first time the idea of SLM was given in (R J Baxley et. all., 2013), within the literature it's been shown that SLM technique will cut back PAPR with less distortion when put next to different strategies. The block diagram of SLM technique is shown in figure 1.

At the transmitter side X parallel bit streams are produced due to the multiplexing of the bit streams of 0s and 1s of the OFDM system. Then this M bit stream which are in parallel leading to the vector :

$\mathrm{M}=[\mathrm{M}[0], \mathrm{M}[1], \ldots \ldots \ldots \ldots \ldots . . . \mathrm{M}[\mathrm{X}-1]]^{\mathrm{T}}$

$\mathrm{M}[\mathrm{k}]$ being for $\mathrm{k}=0$ to $\mathrm{N}-1$ are the symbols which are present in the PSK and QAM. In the traditional SLM techniques $U$ phase vectors are given as

$\mathrm{N}_{\mathrm{U}}=\left[\mathrm{N}_{\mathrm{u}}[0], \mathrm{N}_{\mathrm{u}}[1], \ldots \ldots \ldots . . \mathrm{N}_{\mathrm{u}}[\mathrm{X}-1]\right] \mathrm{T}$

$\mathrm{M}_{\mathrm{u}}[\mathrm{k}]=\mathrm{e}^{\mathrm{j} \Phi \mathrm{n}[\mathrm{k}]}$

where $\Phi_{u}[\mathrm{k}] €(0,2 \pi)$ for $\mathrm{u}=0$ to $\mathrm{u}-1$ with $\mathrm{k}=0$ to $\mathrm{N}-1$. To generate a set of $U$

sequences $\left[\mathrm{M}_{\mathrm{u}}\right]_{\mathrm{u}}=0 \mathrm{u}-1$

And $M_{u}=\left[M_{u}[0], M_{u}[1], \ldots \ldots . ., M_{u}[N-1]\right]^{T} .$.

With components $M_{u}[k]=M_{u}[k] M[k]$

For $\mathrm{u}=0$ to $\mathrm{U}-1$ and $\mathrm{k}=0$ to $\mathrm{N}-1$,

the equation 4 can be written in the form

$\mathrm{M}_{\mathrm{u}}=\mathrm{N}_{\mathrm{u}} \times \mathrm{M}_{\mathrm{u}}=0,1, \ldots \ldots \mathrm{U}-1$

where $\mathrm{x}$ is a product of component.

From the set $\{ \pm 1\}$ or $\{ \pm 1, \pm j\}$ of the phase rotation factors $\mathrm{Nu}$ the integers multiples of $\pi$ and $\pi / 2$ phase shifts are used. Then, the sequences are passed through $\mathrm{U}$. In time domain, $\mathrm{N}$ point IFFTs are given as

$\mathrm{M}_{\mathrm{u}}=\mathrm{IFFT}\left[\mathrm{M}_{\mathrm{u}}\right] \mathrm{u}=0,1, \ldots ., \mathrm{U}-1$

Where $\mathrm{M}_{\mathrm{u}}=\left[\mathrm{M}_{\mathrm{u}}[0], \mathrm{M}_{\mathrm{u}}[1], \ldots, \mathrm{Mn}[\mathrm{N}-1]\right]^{\mathrm{T}}$

Where $F_{\Gamma_{x}}(\gamma)=p_{y}\left(\Gamma_{x} \leq \gamma\right)$ is the cumulative distribution function of $\Gamma_{m}$.

The lowest PAPR is selected for the SLM for all the U candidate sequences.

With components

$\mathrm{M}_{\mathrm{u}}[\mathrm{n}]=\frac{1}{X} \sum_{k=0}^{N-1} M \mathrm{u}[\mathrm{k}] e^{j 2 \pi k n / N}$

$\mathrm{n}=0$ to $\mathrm{N}-1$ 
The PAPR of the cand sequence is calculated as

$$
\operatorname{PAPR}\left\{m_{u}\right\}=\frac{\max _{n=0,1, \ldots-1}\left|m_{u}(n)\right|^{2}}{\frac{1}{N} \sum_{n=0}^{N-1} E\left[\left|m_{u}[n]^{2}\right|\right.}
$$

E[.] I being the expectation.

For the U cand seauence. the scheme selects one which

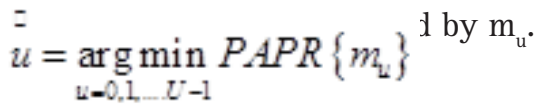

The performance of the scheme for the reduction of PAPR is measured by the Complementary cumulative distribution function (CCDF) which is nothing but the probability that block of OFDM symbol $\mathrm{X}$ is greater than given threshold $\gamma$.

$$
\begin{aligned}
F_{\Gamma_{x}}^{c}(\gamma) & =1-F_{\Gamma_{x}}(\gamma) \\
& =1-p_{\gamma}[\operatorname{PAPR}(m) \leq \gamma] \\
& =p_{\gamma}[\operatorname{PAPR}[m] \geq \gamma]
\end{aligned}
$$

Proposed Method: The conceptual diagram of the proposed method is shown in figure 2. At the transmitter side of the OFDM the bits consisting of 1s and Os are de-multiplexed into parallel bit streams of 1s and 0s.The resultant of this will be vectors from $\mathrm{N}$ parallel bit streams which are mapped independently,

$\mathrm{S}_{\mathrm{i}}(\mathrm{t})=\mathrm{X}=[\mathrm{X}(0), \mathrm{X}(1), \ldots \ldots . . \mathrm{X}(\mathrm{N}-1)]^{\mathrm{T}}$

where $\mathrm{x}[\mathrm{k}]$ for $\mathrm{k}=0,1, \ldots \ldots ., \mathrm{N}-1$ are symbols in a given constellation such as DAPM.

In the random sequence, D special sequences are generated and are applied to the input signals.

The signals are statically independent and are represented as.

$$
A_{i}=\left[e^{j \Phi 0}, \mathrm{e}^{\mathrm{j} \Phi 1}, \ldots \ldots \ldots . . ., \mathrm{e}^{\mathrm{j} \Phi \mathrm{k}-1}\right]^{\mathrm{T}}
$$

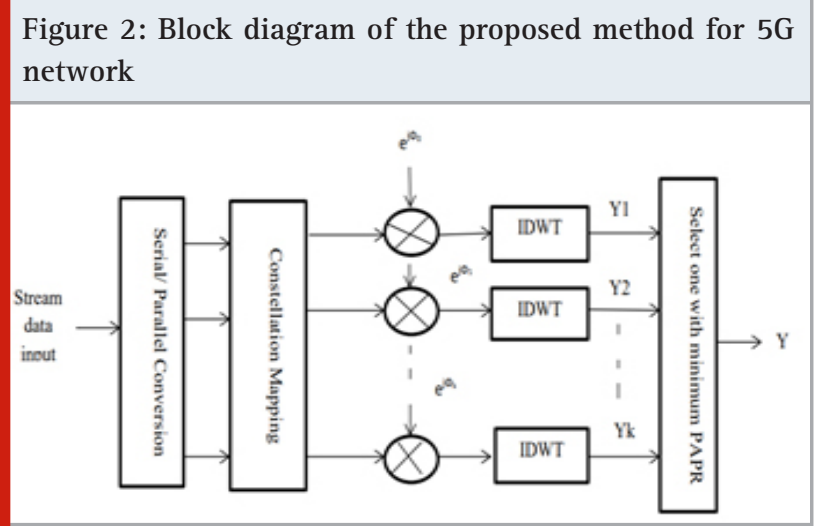

Applying a phase modulation sequence to the OFDM signal yield.

$Y_{i}(t)=\left[S_{i}(t) 0 e^{j \Phi 0}, S i(t) 1 e^{j \Phi 1}, . ., S i(t)_{k-1} e^{j \Phi k-1}\right]$

The output of IDWT corresponding to $y_{i}(t)$ can be given as

$$
y_{i}(t)=I D W T\left\{y_{i}(t)\right\}
$$

\section{Where $1 \leq \mathrm{i} \leq \mathrm{D}$}

Select the signal having minimum PAPR

$$
y(t)=\min _{\mathbb{1}: 0}\left\{y_{i}(t)\right\}
$$

DWT-OFDM: Wavelet refers to a small wave with limited duration. Wavelets form the basis of DWT which are asymmetric as well as irregular. Compared to the Fourier transform, variations in time-frequency resolutions are provided by wavelet transform which is a top advantage over FT. Data is split into different frequency components by the wavelet basis function and in contrast the component is chosen based on its scale. At different frequencies of variable size the wavelet function is split into windows which will cause the variation in time-frequency resolution, unlike the Fourier function that is divided into square windows of fixed sizes which doesn't provide variation in time-frequency resolution. The variation in time-frequency resolution provides

\begin{tabular}{|c|c|c|c|}
\hline \multicolumn{4}{|c|}{$\begin{array}{l}\text { Table } 1 \text {. Amplitude value for } \\
\text { 64-DAPM }\end{array}$} \\
\hline \multicolumn{4}{|c|}{ Last two Amplitude bits } \\
\hline 00 & 01 & 10 & 1 \\
\hline 1 & $\mathrm{~b}$ & $b_{2}$ & $\mathrm{~b}$ \\
\hline $\mathrm{b}$ & $\mathrm{b} 2$ & $\mathrm{~b}_{3}$ & 1 \\
\hline $\mathrm{b}_{2}$ & $b_{3}$ & 1 & $\mathrm{~b}$ \\
\hline $\mathrm{b}_{3}$ & 1 & $\mathrm{~b}$ & $\mathrm{~b}$ \\
\hline
\end{tabular}
functions infinite in number for wavelet transform but only one basis function for Fourier transform.

DWT and IDWT formulas are as given in equations (16) and (17) respectively.

$$
\begin{aligned}
& \mathrm{D}_{\mathrm{k}}=\sum_{\mathrm{k}=0}^{\mathrm{N}-1} \mathrm{~d}(\mathrm{k}) \Psi(2 \mathrm{k}-\mathrm{n}) \\
& d(k)=\sum_{m=0}^{\infty} \sum_{n=0}^{\infty} D_{k} \Psi(2 k-n)
\end{aligned}
$$

Where, $\Psi$ is the wavelet kernel Filters-LPF and HPF are required for practical implementation of DWT with less complexity. The interference is low due to the DWT overlapping properties and hence cyclic prefix is not used in DWT-OFDM systems and a very low data is present in side lobes and majority of the information is being present in the major lobe (N Neurohr et. al., 1998). 
Figure 3: Simulated 64-DAPM constellation diagram.

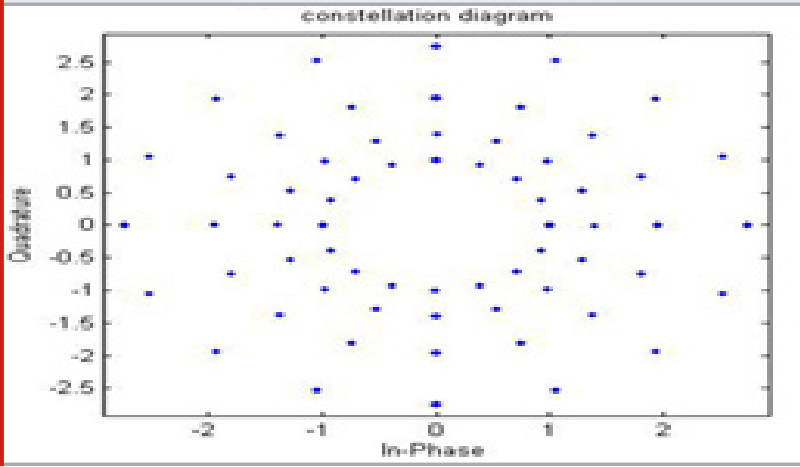

64-DAPM: The bits are modulated into a group of six before they are modulated. The number of subcarriers are the $\mathrm{N}$ number of rows present in the matrix and the subcarriers is the signal from serial to parallel and OFDM symbol represents each column in the matrix. There are six bits out of which 16-DPSK were modulated by first four bits and next two bits are amplitude demodulated in accordance with table (1). (H Y S Xu et. all.,2005).

Perfect Random Sequence: From the discrete time OFDM transmission concept, a constellation plot is created for symbols $\mathrm{N}$ number block of data, where $\mathrm{N}$ is the number of subcarriers to be used. By multiplying the independent phase vectors, a number of independent cand vectors are produced. Consider $\mathrm{X}(\mathrm{k})$ as the mapped sub symbol with data $X$, where, $k=\{0,1,2, \ldots \ldots \ldots . . . N-1\}$. Let the $u^{\text {^th }}$ phase vector be represented as $(\mathrm{u})$, where $\mathrm{u}=\{1,2, \ldots \ldots \ldots \ldots . . \mathrm{U}\}$. $\mathrm{X}(\mathrm{u})$ is the phase vector obtained by multiplying data block with the $\mathrm{u}^{\text {th }}$ candidate vector . So from the $\mathrm{u}^{\wedge}$ th candidate vector to get the $\mathrm{k}^{\wedge \text { th }}$ element equation is represented as

$$
X^{(u)}(k)=X(k) B^{(u)}(k)
$$

IDWT operation is done for each candidate vector to get $\mathrm{U}$ number of alternate OFDM signals, So for the nth symbol of $\mathrm{U}^{\text {th }}$ alternative OFDM signal can be represented as

$$
x^{(u)}(n)=\frac{1}{\sqrt{N}} \sum_{k=0}^{N-1} X^{(u)}(k) e^{j\left(\frac{2 \pi n k}{N}\right)}
$$

For $\mathrm{U}$ number of alternate OFDM, the signal with less PAPR is selected. $x^{(\bar{u})}(k)$ is the selected OFDM signal.

By using the independent phase vectors alternative OFDM symbols will be generated. From equation 18, the $\mathrm{u}^{\wedge \text { th }}$ phase vector for $\mathrm{K}^{\text {th }}$ value is $\mathrm{B}^{\wedge(\mathrm{u})}(\mathrm{k})$ as given in equation 20.

$$
B^{(u)}(k)=e^{j \phi^{(u)}(k)}
$$

$\varphi(\mathrm{k})$ is being the random phase value. Accordingly, the criteria for mutual independence of $b(m)(n)$ and $b(l)(n)$ can be given as

$$
E\left[e^{j \phi}\right]=0
$$

$\phi$ should be distributed uniformly in $[0,2 \pi]$ so as to satisfy the above condition.

Simulation Results: Simulation results of the proposed method are discussed based on two performance indices i.e. PAPR and BER considering AWGN channel in the system with Rayleigh fading.

Papr Performance: Figure 4 shows the PAPR and CCDF performances of the combination of DWT, DCT and DFT with modulation techniques DAPM, QAM and PAM. Here Number of subcarriers are $64,128,256$ with input message size is 1500 bits, Number of cyclic prefix samples=16 and perfect random sequences are selected and the phase rotation factors are 4 with 10 iterations. Figure 4 shows the comparisons of PAPR and CCDF performances with various modulation methods PAM, DAPM and QAM with different transformation such as DWT, DCT and DFT. The results are obtained for all these combinations. The combination of DWT- DAPM gives PAPR of $3.421 \mathrm{db}$ at 10-1 CCDF, DWT-QAM gives 3.929 at 10-1 CCDF and DWT-PAM gives 5.057 at 10-1 CCDF. Similarly all the different combinations of transformation and modulation techniques are tabulated in table II. Figure 5 shows the better modulation technique is DAPM modulation technique that has less PAPR value when compared to other modulation systems. Figure 6 shows that DWT is the better method for PAPR reduction.

Figure 4: PAPR of different transforms and modulation technique.

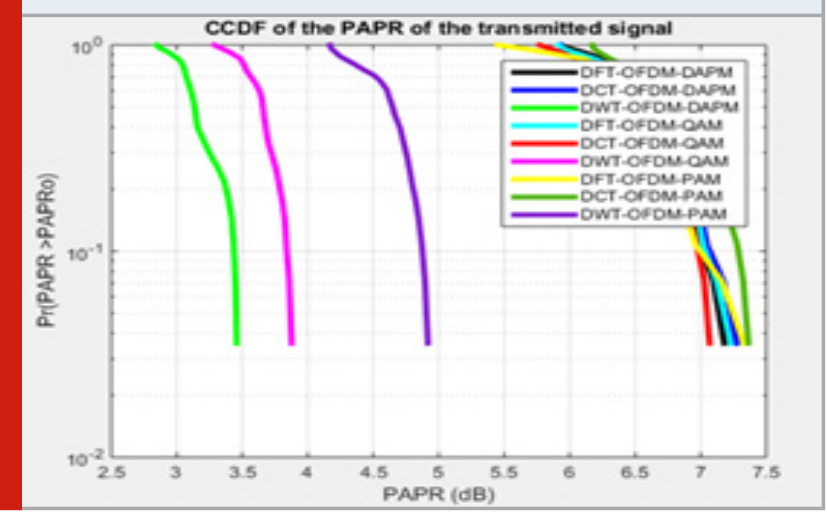

Figure 5: PAPR of different modulation techniques

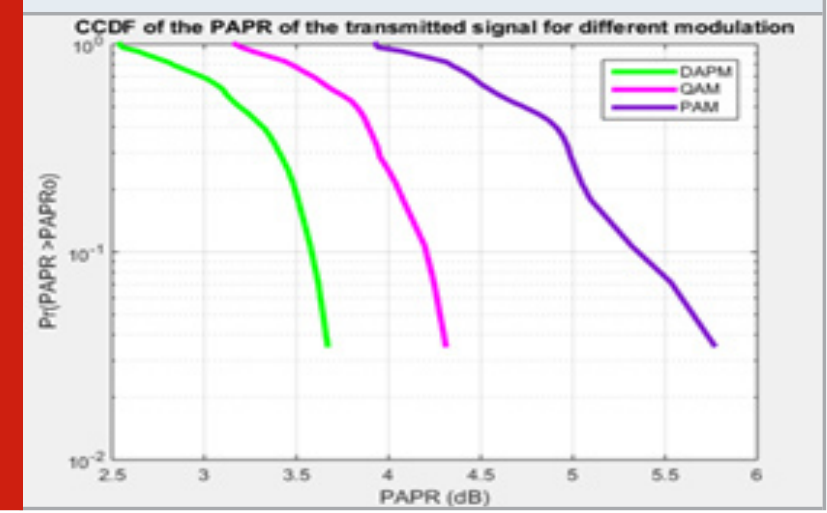


Ber Performance: The performance of this parameter is evaluated by considering modulation techniques. and transforms. Fig. 7, 8, 9, 10 and 11 shows the results of BER performances and these are tabulated in table 3, 4 and 5. In the AWGN channel QAM modulation technique has less BER value because it has only amplitude and there is no phase but in case of frequency selective and flat fading channel the BER is less in DAPM - DWT combination. Table 6 shows the comparison of the proposed system with other systems. In existence. Table 7 shows the considered parameters while simulation.

Figure 6: PAPR performances for different transforms

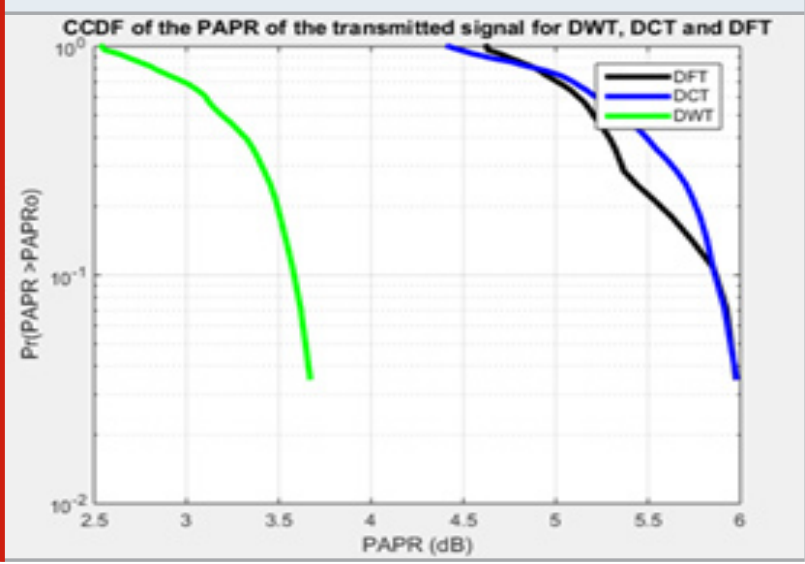

Table 2. PAPR performances for different transforms and modulation technique at 10-1 CCDF

\begin{tabular}{|l|c|}
\hline Modulation technique-Transform & PAPR (dB) \\
\hline DAPM-DWT & 3.421 \\
\hline QAM-DWT & 3.929 \\
\hline PAM-DWT & 5.057 \\
\hline DAPM-DCT & 7.088 \\
\hline QAM-DCT & 7.201 \\
\hline PAM-DCT & 7.146 \\
\hline DAPM-DFT & 7.146 \\
\hline QAM-DFT & 7.146 \\
\hline PAM-DFT & 7.146 \\
\hline
\end{tabular}

Table 3. BER performances of different transforms and modulation technique at $20 \mathrm{~dB}$ SNR.

\begin{tabular}{|l|c|}
\hline Modulation technique-Transform & BER \\
\hline DAPM-DWT & 0.01742 \\
\hline QAM-DWT & 0.0009533 \\
\hline PAM-DWT & 0.1828 \\
\hline DAPM-DCT & 0.0479 \\
\hline QAM-DCT & 0.0133 \\
\hline PAM-DCT & 0.2205 \\
\hline DAPM-DFT & 0.0479 \\
\hline QAM-DFT & 0.04542 \\
\hline PAM-DFT & 0.2205 \\
\hline
\end{tabular}

Figure 7: BER vs SNR for DW, DC EtDF transforms as well as DPCM, PAM, QAM techniques for AWGN Channel.

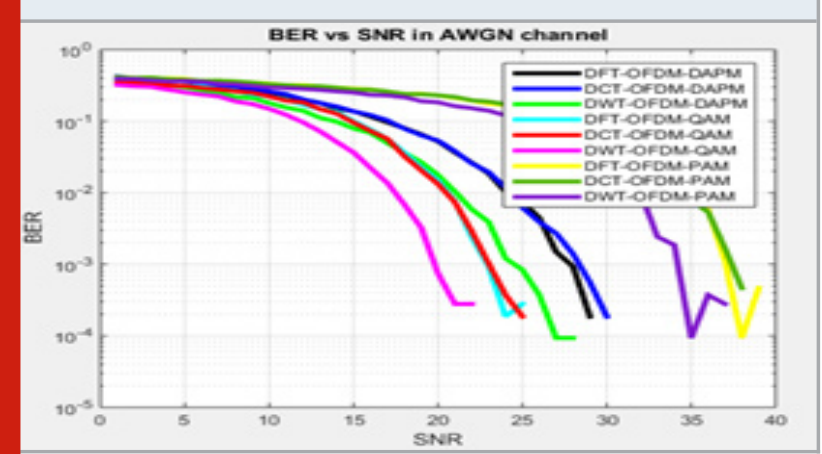

Figure 8. BER vs SNR for different modulation techniques for AWGN channel.

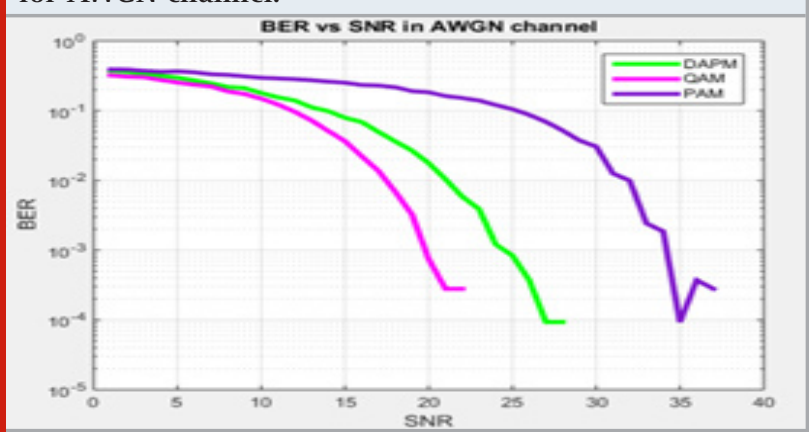

Figure 9. BER vs SNR for DW,DC EDF transforms.

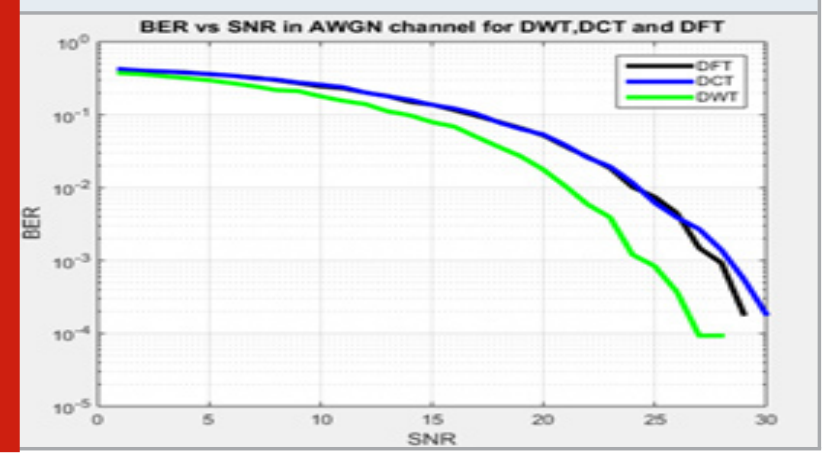

Figure 10: BER vs SNR in flat fading channel for different modulation techniques.

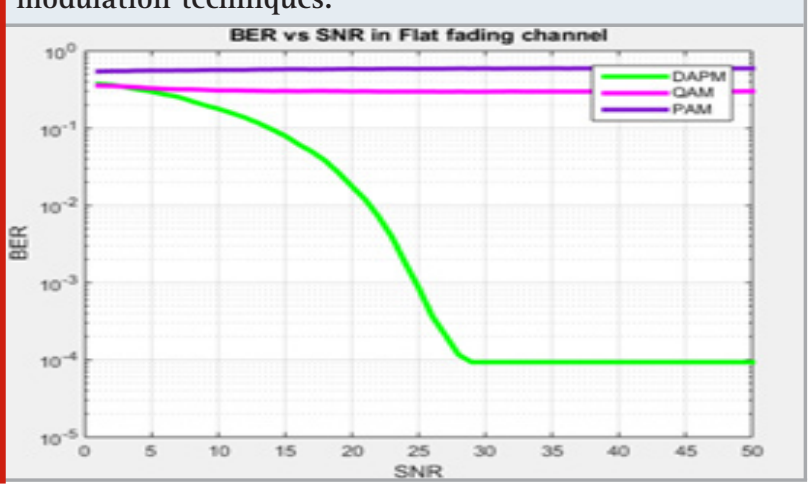


Table 4. BER performances of modulation methods at $20 \mathrm{db}$ SNR for flat fading channel.

\begin{tabular}{|c|c|c|c|}
\hline $\begin{array}{c}\text { Modulation } \\
\text { Technique }\end{array}$ & DAPM & QAM & PAM \\
\hline BER & 0.01783 & 0.6964 & 0.4716 \\
\hline
\end{tabular}

Table 6. PAPR and BER Comparison of the system proposed with the methods in existance

\begin{tabular}{|l|c|c|c|}
\hline $\begin{array}{l}\text { Performance } \\
\text { Indices }\end{array}$ & PAPR (dB) & BER & $\begin{array}{c}\text { Modulation } \\
\text { Technique }\end{array}$ \\
\hline Proposed method & 3.437 & 0.01742 & DAPM \\
\hline Reference 6 & 7.00 & ------- & QAM \\
\hline Reference 7 & 8.6 & ------- & QAM \\
\hline
\end{tabular}

Figure 11: BER vs SNR in frequency fading channel for different modulation techniques.

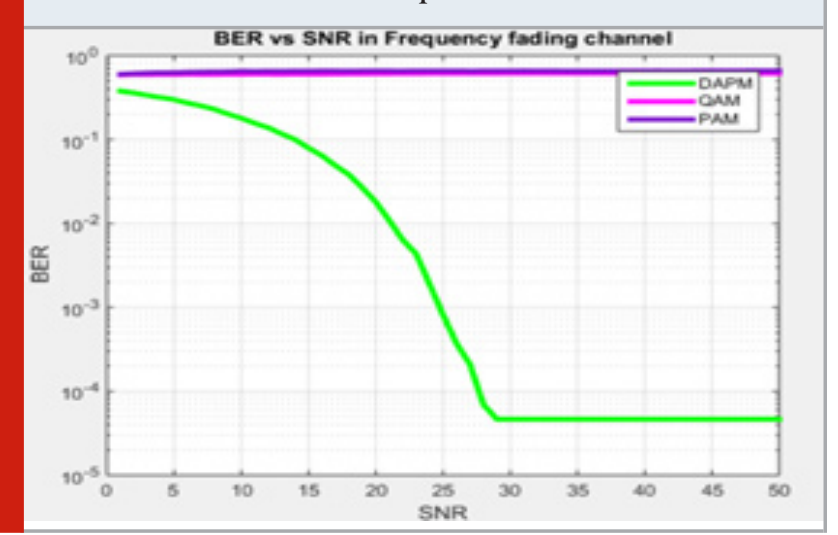

CONCLUSION

In this paper, an efficient PAPR reduction technique for OFDM system is proposed. This scheme employs perfect random sequence with transforms DWT, DCT, DFT and modulation techniques DAPM, QAM, PAM and also it is also modelled with AWGN as well as channels with frequency selective fading and flat fading for reducing the PAPR. Simulation results emphasises that the proposed methodology has less PAPR and BER for DWTDAPM technique which is employed for $5 \mathrm{G}$ networks.

\section{REFERENCES}

D. Li, J. Yu, M. Wang, and S. Zhang, "An improved SLM scheme with low implementation complexity to reduce PAPR performance of OFDM systems," in Proc. IEEE 6th Int. Congr. Image Signal Process. (CISP), vol.

3. Hangzhou, China, 2013, pp. 1499-1503.

G. Wunder, R. F. H. Fischer, H. Boche, S. Litsyn, and J.-S. No, "The PAPR problem in OFDM transmission: New directions for a long-lasting problem," IEEE Signal Process. Mag., vol. 30, no. 6, Nov. 2013, pp. 130-144. H.-B. Jeon, J.-S. No, and D.-J. Shin, "A low-complexity
Table 5. BER performances of different modulation techniques at 20db SNR for frequency selective fading channel.

\begin{tabular}{|c|c|c|c|}
\hline $\begin{array}{l}\text { Modulation } \\
\text { Technique }\end{array}$ & DAPM & QAM & PAM \\
\hline BER & 0.01716 & 0.5033 & 0.687 \\
\hline
\end{tabular}

Table 7. Comparison of the proposed system based on the parameters.

\begin{tabular}{|l|c|c|}
\hline SI No & Considered parameters & System Proposed \\
\hline 1. & No.of Subcarriers & $64,128,512$ \\
\hline 2. & Input message size & 1500 bits \\
\hline 3. & Transformation & DWT, DFT, DCT \\
\hline 4. & Modulation & DAPM, QAM, PAM \\
\hline
\end{tabular}

SLM scheme using additive mapping sequences for PAPR reduction of OFDM signals," IEEE Trans. Broadcast., vol. 57, no. 4, Dec. 2011, pp. 866-875.

H.-B. Jeon, K.-H. Kim, J.-S. No, and D.-J. Shin, "Bitbased SLM schemes for PAPR reduction in QAM modulated OFDM signals," IEEE Trans. Broadcast., vol. 55, no. 3, Sep. 2009, pp. 679-685.

H. Y. S. Xu and H Wang, " An application of dapsk in hf communications, " IEEE Communication Leteers", Vol. 9, July. 2005, pp. 613-615.

Hyun-Seung Joo et. all, "New PTS Schemes for PAPR Reduction of OFDM Signals Without Side Information" IEEE transactions on broadcasting, volume 63, no. 3, Sept. 2017.

J. G. Proakis, Digital Communications. New York, NY, USA: McGraw-Hill, 1995.

L. Wang and J. Liu, "PAPR reduction of OFDM signals by PTS with grouping and recursive phase weighting methods," IEEE Trans. Broadcast., vol. 57, no. 2, Jun. 2011, pp. 299-306.

N Neurohr and M Schilpp, "Comparison of transmultiplexers for modulation multicarrier", IEEE International Conference on Signal Processing (ICSP' 98), Oct. 1998 pp. 35-38.

Paolo Banelli et. all., "Modulation formats and waveforms for 5G Networks: who will be the heir of OFDM" IEEE Signal process. Mag., vol. 31, no.6, Nov. 2014, pp, 80-93.

Pingyuan Yu and Shubo Jin, "A Low Complexity Tone Reservation Scheme Based on Time-Domain Kernel Matrix for PAPR Reduction in OFDM Systems", IEEE Transactions on Broadcasting, volume 61, no.4, December 2015.

Puneeth Kumar D N and M N Eshwarappa “ An Efficient DWT- DAPM Technique for PAPR Reduction in OFDM System" International Journal of Engineering and Advanced Technology, vol.9, no.3, Feb 2020,pp. 16911692. 
R. J. Baxley and G. T. Zhou, "Comparing selected mapping and partial transmit sequence for papr reduction," IEEE Trans. Broadcast., vol. 53, no. 4, Dec. 2007, pp. 797-803.

R. W. Bauml, R. F. H. Fischer, and J. B. Huber, "Reducing the peak-to-average power ratio of multicarrier modulation by selected mapping”, Electron. Lett., vol. 32, no. 22, Oct. 1996, pp. 2056-2057.

S. P. DelMarco, "A constrained optimization approach to compander design for OFDM PAPR reduction," IEEE Trans. Broadcast., vol. 64, no. 2, Jun. 2018, pp. 307-318.

S. Zhang, "Low complex PAPR reduction schemes for OFDM systems," Electronic Theses, Dept. Elect. Comput. Eng., Univ. Windsor, Windsor, ON, Canada, 2016. Si-yu Zhang, Behnam Shahrrava "A Selected Mapping Technique Using Interleavers for PAPR Reduction in
OFDM Systems" wireless personal communication, vol.99, no. 1, Mar. 2018, pp. 329-338.

Si-Yu Zhang, Behnam Shahrrava "A hybrid PAPR Reduction scheme for OFDM systems using perfect sequences" IEEE Transaction on Broadcasting, volume 60, no.1,Mar. 2020, PP.177-186.

S. Zhang, "Low complex PAPR reduction schemes for OFDM systems," Electronic Theses, Dept. Elect. Comput. Eng., Univ. Windsor, Windsor, ON, Canada, 2016.

S. P. DelMarco, "A constrained optimization approach to compander design for OFDM PAPR reduction" IEEE Trans. Broadcast., vol. 64, no. 2, Jun. 2018, pp. 307-318.

Y. Rahmatallah and S. Mohan, "Peak-to-average power ratio reduction in OFDM systems: A survey and taxonomy," IEEE Commun. Surveys Tuts., vol. 15, no. 4, 4th Quart., 2013, pp. 1567-1592. 